\title{
An Interpretative Phenomenological Analysis of Basotho Teenage Mothers' Experiences in Early Motherhood at a Rural School
}

\author{
Kananga Robert Mukuna \\ Psychology of Education, \\ Faculty of Education, Qwaqwa Campus, \\ University of the Free State, South Africa
}

DOI: https://doi.org/10.36941/jesr-2021-0059

\begin{abstract}
This study explored Basotho teenage mothers' experiences in early motherhood at a rural school in a district in South Africa. The interpretative phenomenological qualitative approach and the contextual and phenomenological study designs were used in this study. Five participants $(N=5)$ were purposively selected. Semi-structured interviews were employed as a tool for data collection. Interpretative Phenomenological Analysis (IPA) was used to analyse the data. The findings demonstrated that Basotho teenage mothers experience insufficient support from the family and the school management team. They are expelled from the school during their pregnancy and only allowed to return to school after giving birth. They also lack support from their teenage husbands. Thus, Basotho teenage mothers are stigmatised, discriminated against, and lack support from their teenage husbands, peers, and the community during their early motherhood. The study recommended that the School-Based Support Team (SBST) should train teachers on the best support mechanisms for teenage mothers.
\end{abstract}

Keywords: Basotho teenage mothers, Early motherhood, Interpretative Phenomenological Analysis, Rural school

\section{Introduction}

Over many decades, teenage pregnancy and teenage mothers became a global phenomenon. In South Africa, it has been a significant problem that could affect the psycho-sociological wellbeing of the next generation. The South African Department of Basic Education and the Department of Health are continually concerned about why the rate of teenage pregnancy and the percentage of teenage mothers are greater in rural areas than in urban areas, despite the reforms in educational policy, which introduced sexuality education and AIDS awareness as subjects at intermediate and senior phases in schools. Moreover, the South African government has invested heavily in preventing teenage pregnancy, but its rate has ballooned to alarming proportions (Anastas, 2017). Several attempts have been made to address the matter, with little or no success (James, Van Rooyen \& Strumpher, 2010; du Preez, Botha, Rabie \& Manyathi, 2019; Govender, Naidoo \& Taylor, 2019).

It is important to note that there is a controversy around the occurrence of this phenomenon. For example, in African culture, teenage pregnancy is a blessing and a symbol of teenage fertility (Kyei, 2012). According to Anastas (2017), becoming a mother is a rationale for attaining adult status and independence for a teen mother. Cherry and Dillon (2013) argue that teenage pregnancy and early 
motherhood are considered a natural occurrence, which has been perceived as a poor fit for modern society. On the contrary, Odimegwu, Amoo, and De Wet (2018) argue that teenage pregnancy could result in adverse consequences, such as a high school dropout rate, high abortion rate, and neglected children, which affect the family, the community, and the entire society. Bowman (2013) observes that teenage mothers, especially those from a diverse ethnic background and poor neighbourhood, are often judged as irresponsible, lazy, and have children purposefully receive public assistance. However, some schools treated them differently as individuals who have aspirations and the desire to attain higher educational levels (Klaw, 2008).

Many studies have investigated teenage pregnancy in South Africa. Some studies focused on their experiences (Bhana, Clowes, Morrell, \& Shefer, 2008; Rangiah, 2012; Anastas, 2017). According to Rangiah (2012), peer pressure, lack of parental control, socio-economic status of the family, cultural practices, intimidation, and sexual abuse, and the inaccessibility of health facilities could be causal factors to teenage pregnancies. Teenage pregnancy has been attributed to the transition from adolescence into adulthood and youthful immaturity during their school years (Mkhwanazi, 2013). Some studies revealed that cultural practices and the influence of Child Support Grants (CSG) could increase the birth rate among teenagers in South Africa (Tanga, \& Gutura, 2013; Tanga, Oyeleke \& Gutura, 2015). Bhana (2008) indicates that a fragmented family structure and insufficient support for childcare could affect some African girls under pressure, where parents are absent or working. The lack of sexual education, a poor socio-economic background, alcohol and drug abuse, lack of access to contraceptives, and lack of positive role modelling could all be regarded as causes of teenage pregnancy (Bhana, 2008).

Teenage mothers are referred to as adolescents aged between 11 and 19 years, who become pregnant and parent their children at schooling age (Banke-Thomas, Banke-Thomas \& Ameh, 2017). It is essential to consider that most teenage pregnancies occur between 15 and 19 years of age. However, teenagers in rural areas are becoming mothers in the early stage of their lives without the necessary skills, resources, and support (Chigona \& Chetty, 2008). This could affect their wellbeing and socioacademic development. During this early motherhood period, they encounter many challenges, such as neglect (the feeling of isolation), instability in relationships with their peers, and lack of strong social and family support. The teenage mothers could negatively be perceived and labelled as though they have less dignity, worth, and aspiration than teenage girls. Many teenage mothers postpone their educational attainment and become school dropouts during pregnancy (Birchall, 2018). This is because they have entered the child welfare system and cannot provide financial support to their children (Birchall, 2018).

Bowman (2013) further highlights that teenage mothers are often judged as irresponsible, lazy, and purposefully bearing children to receive public assistance. Therefore, they are rejected and considered incompetent individuals who are unlikely to be successful in school, finding employment, and obtaining high salary earnings (Birchall, 2018). They experience insufficient internal and external support systems and the overwhelming pressure of overcoming the negative stigma. Moreover, they try to fit in at school, which becomes unbearable for them. Therefore, teenage mothers return to school after they have given birth, depending on individual ability. Other scholars investigated teenage mothers who have achieved their outcomes positively. According to Beeler (2016), teenage mothers, who return to complete their high school education, would attend colleges, obtain university degrees, and eventually earn high salaries. Thus, some schools treat them differently as individuals who have aspirations and the desire to pursue education to higher levels (Klaw, 2008).

However, previous studies revealed that teenage mothers without childcare support are less likely to return to school and are sometimes more likely to drop out of school than those who have childcare support (Panday, Makiwane, Ranchod \& Letsoalo, 2015). The reality of childcare is reflected in the gender inequalities in our societies because teenage mothers have many childcare demands such as caring for sick babies, sleep deprivation, finding time to work or study, and the psychosocial needs of new mothers (Morrell, Bhana \& Shefer, 2012). 


\section{Challenges of Teenage Mothers in South African Schools}

It is relevant to mention that teenage mothers are expected to receive support from different sources, such as the school management team, home, and the community. Still, these are insufficient, and in most cases, school management teams do not exist. Many studies report that teachers do not support pregnant teenagers and teenage mothers to manage their adversities for many reasons. These include teachers' inability to do so and judgemental attitudes (Bhana \& Ngabaza, 2012). There are also institutional challenges, including the lack of academic support systems at schools and a lack of counselling, which help combat stigma related to teenage pregnancy and how to cope with parenthood and schooling concurrently. Chigona and Chetty (2008) reveal that many teenage mothers feel that teachers often give up on them and stop helping them academically, and none receives counselling at school. Scholars have been emphatic on the view that discrimination and pressure among pregnant teenagers' classmates could result in insufficient support from school and teachers and force them to drop out of school during pregnancy (Clowes, D’Amant \& Nkani, 2012). Sometimes, principals and teachers seem far more welcoming of learner-parents than pregnant teenagers (Bhana, Clowes, Morrell \& Shefer, 2008). Besides, principals and some teachers often encourage parent learners to leave school and return when they are healthy after giving birth (Department of Basic Education, South Africa [DBESA], 2017). Many teenage mothers reported that they often found it easier to be back in school following childbirth than in the last trimester of pregnancy, as motherhood attracts fewer stigmas than being visibly pregnant (Willan, 2013).

Therefore, it is essential to note that a pregnant girl should be attended by professionally trained nurses who would handle their school cases since they sometimes feel shaky and nauseous, which stimulates vomiting. Morrell, Bhana, and Shefer (2012) observe that very few schools are recognised as having an effective mechanism for offering sufficient support to girls and enabling them to catch up with missed work. In such circumstances, teachers cannot support girls who need to catch up for various reasons, such as time constraints and lack of skills. Teenage pregnancy and teenage mothers are not being considered. Therefore, they are a major part of the education system's challenges in South African schools. David, Van Dyk, and Ashipala (2017) observe that having babies at an earlier age could affect adolescent girls' career. Consequently, this hurts the lives of babies. However, in most cases, having babies earlier results from teenage mothers' failure to succeed at school (Chigona \& Chetty, 2008).

\section{Stigmatisation, Discrimination, and Lack of Support from Peers and the Community}

It is essential to note that pregnant teenagers and teenage mothers experienced unpleasant situations, such as stigmatisation, discrimination, and lack of support from peers and the community. The level of these unpleasant situations determines if pregnant teenagers and teenage mothers would be returning to school the year following childbirth or not. The more hostile the situation would be, the more pregnant teenagers and teenage mothers are likely to experience depression, social exclusion, peer rejection, low self-esteem, poor academic performance, and the low prospect of employment in the future (Panday et al., 2015). Studies have shown that stigmatisation from friends, peers, and the community influences pregnant teenagers and teenage mothers (Morrell, Bhana \& Shefer, 2012). Some scholars revealed unpleasant behaviours, gossiping, teasing, unkind comments, and instances of being shunned by peers, as discouraging pregnant teenagers and teenage mothers from returning to school after giving birth to their children (Shefer \& Bhana, 2012). Sometimes, discrimination, stigmatisation, and traumatisation from community members compel them to change school settings when given childbirth, just to avoid returning to the environment of shame (Morrell, Bhana \& Shefer, 2012). 


\section{The Current Study}

The study, which is an interpretative phenomenological analysis of the Basotho teenage mothers' experiences at a rural school district in South Africa, was guided by the following research questions:

1. What are the experiences of being teenage mothers?

2. What are the effects of becoming teenage pregnant and teenage mothers?

\section{Methodology}

\subsection{Research approach and design}

This study used a phenomenological qualitative approach. According to De Vos, Delport, Fouche, and Strydom (2011), qualitative approaches are useful because they help the researcher to get into the nature of participants' lived experiences in their life world. The study adopted the phenomenological research design, which entails researchers' attempts to capture participant's life worlds, in a way that is not constraining or prescriptive. Participants' life experiences were essential in this study because they helped the researcher contribute to a particular population (Qutoshi, 2018). This study assumed that Basotho teenage mothers, in their social contexts and natural environment, had a more significant opportunity to understand their interpretative phenomenological experiences in a rural school setting.

\subsection{Study participants}

The population consisted of Basotho teenage mothers at a rural high school in Thabo Mofutsanyana District. Purposive and convenience samplings techniques were used in selecting participants for this study. According to Creswell (2013), purposeful sampling consists of identifying possible participants who understand the research problem and the study's central phenomenon. A sample size of four $(\mathrm{N}=4)$ participants were selected at a rural school. This study considered the inclusive criteria for the selection of participants into the sample. The study considered only teenage mothers, parenting, and unmarried, who have returned to school after giving childbirth as participants. They had spoken Basotho as a home language, and their ages ranged from 16 to 20 years. Besides, it was advantageous to use the home language in this study because participants were from a natural setting. The researcher believed that participants could easily express their thoughts and points of view at length, in personal and unique ways (Babbie, 2011). All the participants were female learners enrolled at a selected rural school and lived within the Thabo Mofutsanyana District in the Free State Province.

\subsection{Measures}

This study employed in-depth semi-structured interviews to collect the data. The interview questions were concerned with the participants' points of view relating to experiences of being Basotho teenage mothers and the effects of becoming pregnant teenagers and, subsequently, teenage mothers. The questions were open and in Sesotho Language to allow them to respond freely to questions and to express their own opinions of their lived experiences at school settings. The interviews were audiorecorded and transcribed and then translated from Sesotho to English.

\subsection{Procedure}

Ethical clearance was obtained from the Research and Ethics Committee of the University of Free State. Thereafter, the Department of Education granted authorisation to the researcher to access the selected high schools in Thabo Mofutsanyane District. The recruitment process adhered to an inclusion criterion related to the location, ethnic, and cultural background of the participants. A rural high school was identified conveniently due to its easy accessibility to teenage mothers. The researcher contacted 
the principal of the selected school for a meeting to assist in identifying teenage mothers within the school. The researcher invited the teenage mothers to the meeting and requested them to contribute to the study's development of knowledge. All the participants were informed of their contribution to the research and their right to voluntarily participate or withdraw at any time. The researcher observed that they felt uncomfortable during the process. All of them expressed their interest, availability, and willingness to be interviewed in this study. However, after the participants' consent to participate in this study was verbally granted, personal and parental written consent forms were given to them requesting their approval since they were still under parental care.

Finally, all the consent forms were signed by the participants and their parents or guardians for ethical considerations. All interview processes were conducted after school in the school's boardroom for convenience's sake. The interview sessions were conducted in the Sesotho Language and took approximately twenty minutes. An audio-recorder was used with the permission of participants in this study. Pseudonyms were also used to conceal the identity of the participants in this study.

\subsection{Data analysis}

This study used the Interpretative Phenomenological Analysis (IPA). Its purpose was to explore how participants interpreted their individual life experiences in the social world to assume existing universal inclination towards self-reflection (Smith, Flowers \& Osborn, 2013). It was useful since it allowed the researcher to listen to the participants' descriptions of the investigated phenomenon process in a receptive manner (Eddles-Hirsch, 2015). The IPA was adopted because of its flexibility and versatility, designs that enhance an understanding of the individual's lived experiences (Tuffour, 2017).

However, the IPA was rooted in the phenomenology of hermeneutic and interactionism, which acknowledges that the meaning of individually attributed events is only accessible via an interpretative process (Eddles-Hirsch, 2015). IPA, together with thematic and narrative analyses, is a useful gateway into the often mystifying world of qualitative analysis (Shaw, 2010). It is important to note that IPA is a cyclical process, which involved various stages, from the combination textual to the structural descriptions, which demonstrated the essence of the phenomenon being investigated (Eddles-Hirsch, 2015). Similarly, the conception of the researcher in the interpretation process of IPA mainly played a significant role in giving meaning to the personal world being investigated.

The interviews were voice-recorded, transcribed, and where necessary, translated from Sesotho into English with meticulous accuracy, including indications of pauses, apparent mistakes, and speech dynamics. The IPA looked for themes in the first cases. The initial stage was textual analysis, which focused on identifying patterned meaning across a data set. It also involved a close reading of transcripts to familiarise them with the essence of knowledge intimately. The margin was documented into emerging theme titles, and then the initial notes were converted into precise sentences consisting of capturing the consistent quality of the information found in the text (Smith \& Shinebourne, 2012; Alase, 2017). The preliminary themes were then identified, and the response moved to a slightly higher level of abstraction. There was a connection with other cases. It is important to note that the number of developing themes reflected the pertinence of the particular passage.

The next stage was an iterative analysis, which consisted of making sense of the connecting themes that emerged from the data set. Then, the themes were clustered, which attempted to provide a complete structure of the analysis related to the themes identified in clusters or concepts (EddlesHirsch, 2015; Alase, 2017). The purpose of this stage involved group themes and identified them into superordinate categories, which suggested a hierarchical relationship between themes. According to Alase (2017), the final phase focuses on moving from tabulating themes to writing up, and the last statement outlines the meaning inherent in the participant's experiences.

\section{Results}

The study explored the experiences of teenage mothers during their early motherhood. Data were 
analysed using the Interpretative Phenomenological Analysis. The main themes that emerged include the experiences of being Basotho teenage mothers and the effects of becoming pregnant teenagers during the early stages of motherhood.

\subsection{Experiences of being Basotho teenage mothers}

The sub-themes which emerged were unawareness of being pregnant, initial reactions to the discovery of pregnancy, and challenges of being teenage mothers.

\subsubsection{Unawareness of being pregnant}

The findings demonstrated that Basotho teenage mothers were oblivious to their pregnancy. They revealed that they were ignorant of their situation, and most of them discovered their pregnancy late in the second trimester. The teenage mothers intimated that the public and the family informed and accused them of being pregnant. Hence, as always, they refused and denied the accusation when confronted directly about the matter. This is illustrated by the following responses from some of the participants.

\footnotetext{
"My mum was [the] one who told me that I was pregnant. I was not even aware of my pregnancy" (Participant 1).

"My teenage husband even told me that I was pregnant" (Participant 2).

"One of my classmates also told me that I was pregnant" (Participant 3).

"One of my roommates in the hostel told me that I was pregnant. I refused, and even my Life-Orientation teacher also confronted me and told me that I was pregnant, but I refused" (Participant 5).
}

From these interview excerpts, it is clear that most teenage mothers were unaware of their pregnancy when it occurred. Precisely, the participants were ignorant of the signs of pregnancy.

\subsubsection{Initial reactions of shock and denial}

The findings showed that Basotho teenage mothers initially experienced a wide range of emotions, including denial, crying, shock, nervousness, fear, and disbelief when they discovered their pregnancy. Basotho teenage mothers generally denied their condition until the results of the pregnancy test came out positive. Furthermore, they revealed that it was difficult to tell their mothers about pregnancy. They even acknowledged that they were tempted to commit abortion, but they did not know how to do it. The following excerpts from three participants help illustrate these findings:

\footnotetext{
"I believed that I could not fall pregnant because I only had sex once. I was shocked and stressed. I nearly committed suicide" (Participant 1)

"I could not confront my mother about the matter, I was nervous and shocked. I even asked the nurse about the procedure to be followed when terminating a pregnancy" (Participant 2).

"I was scared as I was worried about how I was going to tell my mother about my pregnancy" (Participant 3).
}

During the interview sessions, one participant explained that she had so much emotional distress that she even locked herself in her room in a hostel for the whole day after finding out that she was pregnant. Moreover, she cried the whole day and wanted to commit abortion, but her roommates advised her otherwise. When schools were closed for the term, she was scared of going home and face her mother since the pregnancy had made her belly bulge. 


\subsubsection{Stigmatisation, embarrassment, and discrimination}

The findings revealed that Basotho teenage mothers experienced stigma, embarrassment, and discrimination during pregnancy and early motherhood. They felt guilty and embarrassed. They all recalled that they were labelled as irresponsible and considered individuals who could not make informed decisions. They were also labelled as individuals who lacked the ambition to succeed in academic circles. Their community also criticised them and had negative perceptions about teenage pregnancy and teenage motherhood. Basotho teenage mothers believed that society is continuously judging and perceiving them as having committed a crime. They further felt that the community perceived them as nothing but a burden to the government, as they were welfare reliant. They revealed that when they returned to school after delivery, they were ridiculed by teachers and classmates who perceived them as irresponsible and misbehaving learners. One participant reported that:

\footnotetext{
"[They perceived] a teen mother [as an] irresponsible person, who is misbehaving, but it does not affect me in any way as I know myself, and I even told myself to prove them wrong" (Participant 1).

"At the school, other teachers did not support me at all because I was almost expelled. Some teachers considered me a naughty girl" (Participant 2).
}

From these interview excerpts, teenage pregnancy made the girls experience discrimination and stigmatisation from peers, teachers, and community members. This negatively affected their psychological wellbeing and social lives.

\subsubsection{Trauma and pains}

The findings also indicated that Basotho teenage mothers experienced trauma and pain during pregnancy. Most of them revealed that they lacked labour preparation and were ignorant of post-natal consultation and expectations since it was their first experience. They emphasised that trauma could be the source of their emotional distress. The following responses from some of the participants help illustrate these findings:

\footnotetext{
"I almost gave birth in the schoolyard on a Friday, and the following Monday, I had to come for my examination while I was still not fine. I had given birth naturally so I could not walk properly, so my classmates were looking at me. Others were even laughing at me, and that incident made me feel stressed" (Participant 1).

"I found it difficult to categorise myself in terms of what stage of life I was when I gave birth because the pain I went through was so unbearable" (Participant 3).

"I did not know to expect (sic) as I was still young when I got into the maternity ward! I was as traumatised as I was the youngest in that ward, and even those older than I was screaming. I even fainted when I woke up; the baby was born. Labour pains are not a child's play" (Participant 3).

"I had stress when I was pregnant, as I did not know what to expect. On the other hand, my teenage husband was not there. I had to go through that stage alone" (Participant 4).

"Some of my teachers are traumatising me. For example, sometimes, when I get the answer incorrect, my teacher would 'say being a mother and learner will never mix', she even said I am not studying (sic), and I should not forget that I am no longer a kid. If I become absent from school for some reason, some teachers would say to me is (sic) because I now have many responsibilities even before they hear from me why I was absent"(Participant 2).
}

From the above interview excerpts, it is apparent that the Basotho teenage mothers were being traumatised by teachers in class for many reasons. This was because they had changed their social status in both ways as school children and treated as such, and as mothers and expected to be mature adults responding to some responsibilities. 


\subsection{Effects of becoming Basotho pregnant teenager at early motherhood stage}

The participants revealed that becoming teenage mothers affected them in several ways. This study showed that teenage pregnancy and teenage motherhood among Basotho teenage mothers affected their physical structure and emotional, spiritual, and cultural life.

\subsubsection{Academic effect}

The findings revealed that being Basotho, pregnant teenagers and teenage mothers negatively affected their academic performance. Two of them confirmed that they dropped out of school when they became pregnant, and they repeated the same grade the following year after childbirth. The responses from the two participants are as follows:

"I can say being a teenage mother affected me negatively when I was pregnant because I had to stay at home when I was about to give birth as instructed by the school management team. The management expelled me from the school, whereas I did not have any complications related to pregnancy" (Participant 4).

"Academically, I had been affected as I had to drop out of school when I was pregnant. This year, I believe I would be in Grade 11 not repeating Grade 10 for the second time (sic)" (Participant 5).

On the contrary, the participants' remaining transcripts acknowledge that being Basotho pregnant teenagers did not affect their academic performance. However, they were encouraged by both teachers and mothers to continue and were never disturbed in their schooling. Consequently, all of them managed to pass their examinations, although they were pregnant. The responses from the three participants are as follows:
"My academic performance is not affected in any way as I managed to pass in June, although I gave birth at the end of May just before I start with (sic) my June examination. I gave birth on [a] Friday [and] the following Monday, I started my exam" (Participant 1).
"I managed to pass my Grade 11 although I wrote my final examinations while I was seven months pregnant" (Participant 2).
"I was not affected in any way because I managed to pass; I never repeated any class" (Participant 3).

\subsubsection{Emotional effect}

The results showed that Basotho teenage mothers were emotionally affected during their pregnancy. They revealed that they were very stressed because it was unexpected, and some teachers discriminated against and labelled them. The participants had this to say:

"Sometimes, when I get the answer incorrect, the teacher would remark that being a mother and learner will never mix. She even saying (sic) I am not studying, and I should not forget that I am no longer a kid" (Participant 2.

"I almost gave birth in the schoolyard, so the following Monday, I had to come for my examination though I was still not fine" (Participant 1).

"The teacher would even say I am not studying (sic), and I should not forget that I am no longer a kid. If I become absent from school for some reason, some teachers would say to me is (sic) because I now have many responsibilities even before they hear from me why I was absent" (Participant 2).

"I was still not fine as I gave birth naturally. I could not walk properly, and so my classmates would look at me. Others would even laugh at me, and that incident stressed me" (Participant 3).

"What stresses me sometimes is the fact that I find it difficult to categorise herself in terms of what stage of life I am. I had stress when I gave birth because the pain she went through was so unbearable. I did not know to expect as she was still young when I got into maternity ward iyooh!" [Exclaiming] (Participant 3).

"I had stress when I was pregnant as I did not know what to expect; on the other hand, my teenage 
husband was not there. I had to go through that stage alone" (Participant 4).

"I went through a lot of stress during my pregnancy, as my parents did not support me at all. At some point, I even thought of taking my own life because my family made me feel useless" (Participant 5).

\subsubsection{Physical effect}

The results demonstrate that Basotho teenage mothers were also physically affected as their body structure changed after childbirth. They revealed that they were still the same despite the bodily changes that included stretch marks on their stomachs. The responses from some participants are as follows:

\footnotetext{
"As I gave birth naturally, I could hardly walk properly. So my classmates were looking at me. Others were even laughing at me, and that incident stressed me" (Participant 1).

"Physically, my body structure is still the same, although I have stretch marks on my stomach. That is not a problem at all as I was not used to wearing too revealing clothes even before I gave birth" (Participant 1).

"My body has changed due to stretch marks; I had to change my dressing style" (Participant 2).

I was still not okay as I gave birth naturally. So I could not walk properly" (Participant 3).
}

Most Basotho teenage mothers revealed that they experienced various pregnancy symptoms, such as vomiting, fatigue, and temper loss. They further indicated that they got assistance and confirmation of the pregnancy from nurses at the clinics. Two participants illustrated this point, thus:

"I vomited, I was short-tempered, and I experienced a lot of fatigue" (Participant 2).

"My periods disappeared, and I remembered that when I started to menstruate (sic), my mum told me that if periods stop, it means pregnancy" (Participant 3).

\subsubsection{Spiritual and cultural effects}

The results showed that Basotho teenage mothers were negatively affected in their spiritual life when they discovered their pregnancy. They confided in the researcher that having unwanted pregnancy was an offense to their belief systems and culture. Hence, the belief systems did not allow the girls to conceive before marriage, and they were forced to stop attending church services since they were found to be pregnant. The responses from the two participants are as follows:

"I was negatively affected as I was one of [the] youth choir members in our church. So, having a child before marriage is misconduct according to the rules of our church. The church said I sinned, so I was suspended for six months" (Participant 1).

"It affected me negatively because, from the time I discovered that I was pregnant, I did not attend church anymore" (Participant 3).

Contrary to cultural expectations, Basotho teenage mothers felt that their families did support them during their pregnancy.

"I went through a lot of stress during my pregnancy, as my parents did not support me at all. At some point, I even thought of taking my own life because my family made me feel useless" (Participant 5).

From the above interview excerpts, one can safely conclude that becoming Basotho pregnant teenagers and teenage mothers negatively affected their academic performance and achievement and their emotional, physical, spiritual, and cultural life. This was mainly exacerbated by a lack of support systems, including peers, family, school, and the community. 


\section{Discussion}

This study demonstrated that Basotho teenage mothers experienced many challenges before giving birth. They were unaware of their pregnancy as a result of ignorance regarding what the condition entailed. These findings concur with the results from previous studies, in which teenagers were ignorant of being pregnant (Varga, 2003; Mkhwanazi, 2013). The results further indicate that various reactions were observed initially when Basotho teenage mothers discovered their pregnancy. They went through various emotional experiences, including denial, stress, shock, and fear when they were found to be pregnant in the family. Similar results were found in previous studies (Panday et al., 2015; Mkhwanazi, 2013; Chohan \& Langa, 2011; Akella \& Jordan, 2014). The study also revealed that becoming teenage mothers affected their physical structure and emotional, spiritual, and cultural lives. It was complicated for teenage mothers to juggle pregnancy, parenthood, and schooling. This is supported by previous studies that identified teenage pregnancy as capable of breaking down religious, traditional, and cultural values in a girl's life (Appiah-Sekyere \& Awuah-Nyamekye, 2012).

This study also revealed that Basotho teenage mothers experienced various challenges when they returned to school. They were stigmatised, embarrassed, discriminated against, and treated as irresponsible children by some teachers. The study noted the inconsistency of policy and practice in public education, in which the policy stipulates that learner pregnancy should be considered as special needs with access to counselling by professionals, with the principal of the school managing and coordinating the process (DBE, 2017; Chigona \& Chetty, 2008). On the contrary, Chohan (2012) highlights that pregnant teenagers were stigmatised by their teachers and fellow learners, who made them feel disinterested in classroom activities.

Similarly, parents' teenage mothers reported their disappointments on hearing that teachers ridiculed their daughters, which led them to display negative social, judgemental, and discriminatory attitudes towards schools (Mkhwanazi, 2013). In or outside marriage, giving childbirth is traditionally considered an ultimate rite is epitomising the passage to womanhood, thus elevating a girl's social status (Jewkes, Morrell \& Christofides, 2009). Therefore, some scholars argue that this confuses teenage mothers, who are treated as children but still expected to act like adults (Jewkes, Morrell \& Christofides 2009; Chohan \& Langa, 2011). Therefore pregnant teenagers and teenage mothers; however, community members isolated and labelled them from others (Chohan, 2010). Furthermore, parental disapproval of their child associating with pregnant teenagers and teenage mothers is risky to contaminate others in the communities.

Furthermore, the results show that teenage mothers were traumatised at school, and it was painful to be responsible for childcare. This is consistent with previous literature, which supported that as primary caregivers, it was very difficult for the new teenage mothers to return to school, as they had to attend to psychosocial issues such as childcare, caring for sick babies, sleep deprivation, and difficulty in finding time to study (Grant \& Hallman, 2008; Panday et al., 2015). The reality of childcare preventing many teenage mothers from returning to school is gender-based and reflects the gender inequalities in African societies (Morrell, Bhana \& Shefer, 2012; Jewkes, Morrell \& Christofides, 2009). These results corroborated with previous studies in which teenage girls were seen to lack expectations and to have insufficient skills to cope with adversities. Hence, they encounter specific challenges that could compromise their school performance (Chohan \& Langa, 2011).

\section{Conclusion}

This study concludes that although the prevalence of pregnancy ought to be prevented among teenage girls at rural high schools in South Africa, it is recommended that stakeholders should concentrate on developing interventions that reduce the number of young teenage mothers.

They need support to overcome the challenges mentioned above to sustain their wellbeing. Instead of social workers trying to provide teenage mothers with resources to succeed academically and focus on family wellbeing, they tend to focus on pregnancy prevention. Comprehensive sexuality 
education should be incorporated into Life-Orientation lessons to assist girls and boys to practise safe sex. Teachers should be trained comprehensively to assist teenage mothers with childcare support since teenage mothers are still young and have many responsibilities. The School-Based Support Team (SBST) should be active in each school to provide training to teachers. This would help them give appropriate support to teenage mothers, as teenage pregnancy and teenage motherhood are learning barriers. However, literature has shown that teenage mothers receiving childcare support are likely to return to school and complete their studies. Therefore, it is recommended that both paternal grandmothers and maternal grandmothers help teenage mothers with childcare support to continue with their studies and become better and self-reliant individuals in the future. The schools and clinics should assist in the social development of teenage mothers by informing them about the procedure to access social grants.

\section{References}

Akella, D., \& Jordan, M. (2014). Impact of social and cultural factors on teenage pregnancy. Journal of Health Disparities Research and Practice, 8(1), 41-61. http://digitalscholarship.unlv.edu/jhdrp/.

Alase, A. (2017). The interpretative phenomenological analysis (IPA): A guide to a good qualitative research approach. International Journal of Education and Literacy Studies, 5(2), 9-19. https://doi.org/10.7575/aiac.ijels.v.5n.2p.9.

Anastas, J. W. (2017). What's the story? Views of pregnant teens in qualitative research. Affilia, 32(2), 133-170.

Appiah-Sekyere, P., \& Awuah-Nyamekye, S. (2012). Teenage pregnancy in the life and thought of the traditional Akan: moral perspectives. Integr Humanism Journal, 2(2), 131-138.

Babbie, E. R. (2011). Introduction to social research. Wadsworth Cengage learning. (5th ed.). Belmont, CA: Cengage Learning/Wadswort.

Banke-Thomas, O. E., Banke-Thomas, A. O., \& Ameh, C. A. (2017). Factors influencing utilisation of maternal health services by adolescent mothers in Low-and middle-income countries: a systematic review. BMC pregnancy and childbirth, 17(1), 65. https://doi.org/10.1186/s12884-017-1246-3.

Barr, N., (2012). Economics of the welfare state (5th. Ed.). Oxford: Oxford University press.

Beeler, S. (2016). Undergraduate single mothers' experiences in postsecondary education. New Directions for Higher Education, 176, 69-8o. https://doi.org/10.1002/he.20210.

Bhana, D Clowes, L., Morrell, R. \& Shefer, T. (2008). Pregnant girls and young parent in South African schools. Agenda 22, no. 76, 78-90.

Bhana, D. (2008). 'Girls hit!'Constructing and negotiating violent African femininities in a working-class primary school. Discourse: studies in the cultural politics of education, 29(3), 401-415. https://doi.org/10.1080/01596300802259160.

Bhana, D., \& Ngabaza, S. (2012). Teachers' responses to pregnancy and young parents in schools. In R. Morrell, D. Bhana, \& T. Shefer (Eds.), Books and/or babies: Pregnancy and young parents in school, (49-62). Cape Town, HSRC Press.

Bhana, D., Clowes, L., Morrell, R., \& Shefer, T. (2008). Pregnant girls and young parents in South African schools. Agenda, 22(76), 78-9o. https://doi.org/10.108o/10130950.2008.9674935.

Bhana, D., Morrell, R., Shefer, T. \& Ngabaza, S., (2010). South African teachers' responses to teenage pregnancy and teenage mothers in schools. Culture, health $\mathcal{E}$ sexuality, 12(8), 871-883.

Birchall, J. (2018). Early marriage, pregnancy and girl child school dropout. Independent researcher and consultant. Available October 2018. https://opendocs.ids.ac.uk/opendocs/bitstream/handle/20.500.12413/14285 /470_Early_Marriage_Pregnancy_and_School_Dropout.pdf?sequence=1. Retrieved 28 December 2019.

Bowman, S. J. (2013). From Her Perspective: Reflections of Teenage Pregnancy and Parenthood. Retrieved from Sophia, the St. Catherine University repository website: https://sophia.stkate.edu/msw_papers/155.

Cherry, A. L., \& Dillon, M. E. (2013). Teenage pregnancy. London: Oxford University Press.

Chigona, A. \& Chetty, R., (2008). "Teen mothers and schooling: lacunae and challenges. South Africa Journal of education, 28 (2), 261-282.

Chohan, Z. C. (2012). Deconstructing teenage pregnancy: teenage mama's talk about the self. Doctoral dissertation. Johannesburg: University of the Witwatersrand.

Chohan, Z., \& Langa, M. (2011). Teenage mothers talk about their experience of teenage motherhood. Agenda, 25(3), 87-95. https://doi.org/10.1080/10130950.2011.610993.

Clowes, L., D'Amant, T. \& Nkani, V., (2012). School principals and their responses to the rights and needs of pregnant and parenting learners. HSRC Press. 
David, S. A., Van Dyk, A., \& Ashipala, D. O. (2017). Experiences of young adolescent mothers regarding adolescent motherhood in Oshana region. Journal of Nursing Education and Practice, 7(12), 39-51. https://doi.org/10.5430/jnep.v7n12p39.

De Vos, A.S., Delport, C. S. L., Fouche, C. B. \& Strydom, H., (2011). Research at grassroots: A primer for the social sciences and human professions. Van Schaik Publishers.

Department of Basic Education (DBE) (2017). Department of Basic Education National Policy on HIV, STIs and TB. Pretoria, South Africa: Available at. https://serve.mg.co.za/content/documents/2017/o6/14 /dbehivtbpolicyfinaljune2017cabinetapproved.pdf. Accessed 22 December 2019.

du Preez, A., Botha, J. A., Rabie, T., \& Manyathi, D. G. (2019). Secondary school teachers' experiences related to learner teenage pregnancies and unexpected deliveries at school. Health SA Gesondheid (Online), $24,1-7$.

Eddles-Hirsch, K. (2015). Phenomenology and educational research. International Journal of Advanced Research, 3(8), 251-26o. Available at: http://www.journalijar.com/article/5631/phenomenology-and-educationalresearch/. Retrieved on 16 December 2019.

Govender, D., Naidoo, S., \& Taylor, M. (2019). Knowledge, attitudes and peer influences related to pregnancy, sexual and reproductive health among adolescents using maternal health services in Ugu, KwaZulu-Natal, South Africa. BMC public health, 19(1), 928. https://doi.org/10.1186/s12889-019-7242-y.

James, S., Van Rooyen, D., \& Strumpher, J. (2010). A model for the facilitation of intergenerational reconciliation in teenage pregnancy: a Xhosa perspective. Africa Journal of Nursing and Midwifery, 12(2), 3-13.

Jewskes, R., Morrell, R., \& Christofides, N. (2009). Empowering teenagers to prevent pregnancy: lessons from South Africa. Culture, health \& sexuality, 11(7), pp. 665 - 688.

Klaw, E. (2008). Understanding Urban adolescent mothers' versions of the future in terms of possible selves. Journal of Human Behavior in the environment, 18 (4) pp. 441 - 462. https://doi.org/10.1080/10911350802486767.

Kyei, K. A. (2012). Teenage fertility in Vhembe District in Limpopo Province, how high is that?. Journal of Emerging Trends in Economics and Management Sciences, 3(2), 134-140.

Lévesque, S., \& Chamberland, C. (2016). Intimate partner violence among pregnant young women: a qualitative inquiry. Journal of interpersonal violence, 31(19), 3282-3301. https://doi.org/10.1177/o886260515584349.

Mkhwanazi, N., (2013). Books and Babies: Pregnancy and Young Parents in Schools edited by Robert Morrell, Deevia Bhana and Tamara Shefer.

Morrell, R., Bhana, D. \& Shefer, T., (2012). "Pregnancy and parenthood in South African schools." Books and babies: Pregnancy and young parents in schools, pp. 1- 30.

Odimegwu, C. O., Amoo, E. O., \& De Wet, N. (2018). Teenage pregnancy in South Africa: Where are the young men involved?. South African Journal of Child Health, 12, 44-50. http://doi.org/10.7196/sajch.2018.v12i2.1523.

Panday, S., Makiwane, M., Ranchod, C. \& Letsoala, T., (2015). Teenage pregnancy in South Africa: with a specific focus on school-going learners. Child, Youth, Family and Social Development, Human Sciences Research Council (Council for Research on Children, Youth, Family and Social Development and Human Sciences). Department of Basic Education, Pretoria.

Qutoshi, S. B. (2018). Phenomenology: A philosophy and method of inquiry. Journal of Education and Educational Development, 5(1), 215-222.

Rangiah, J. (2012). The experiences of pregnant teenagers about their pregnancy. Doctoral dissertation, Stellenbosch: Stellenbosch University.

Shaw, R. L. (2010). Book Review: On Being Thrown into Phenomenological Research: Jonathan A. Smith, Paul Flowers and Michael Larkin, Interpretative phenomenological analysis: Theory, method and research. Journal of Health Psychology, 15(2), 310-312. https://doi.org/10.1177/1359105309355859.

Smith, J. A., \& Shinebourne, P. (2012). Interpretative phenomenological analysis. American Psychological Association. In H. Cooper, P. M. Camic, D. L. Long, A. T. Panter, D. Rindskopf, \& K. J. Sher (Eds.), APA handbooks in psychology ${ }^{\circledast}$. APA handbook of research methods in psychology, Vol. 2. Research designs: Quantitative, qualitative, neuropsychological, and biological (pp. 73-82). American Psychological Association. https://doi.org/10.1037/13620-005.

Smith, J. A., Flowers, P., \& Osborn, M. (2013). Interpretative phenomenological analysis and the psychology of health and illness. In Material discourses of health and illness (pp. 77-100). Routledge.

Tanga, P. T., Oyeleke, I. A., \& Gutura, P. (2015). Influence of Child Support Grants on Increased Birth Rate among Women of Childbearing Age in Alice Town, South Africa. Journal of Human Ecology, 52(3), $236-245$.

Tanga, P., \& Gutura, P. (2013). The Impact of the Child Support Grant on Participation in the Labour Market in Rural Eastern Cape. Social Work/Maatskaplike Werk, 49(1), 128-140. https://doi.org/10.15270/49-1-8o.

Tuffour, I. (2017). A critical overview of interpretative phenomenological analysis: a contemporary qualitative research approach. Journal of Healthcare Communications, 2(4), 52. https://doi.org/10.4172/2472-1654.100093. 
Varga, C. A. (2003). How gender roles influence sexual and reproductive health among South African adolescents. Studies in family planning, 34(3), 160-172. https://www.jstor.org/stable/3181103.

Willan, S. (2013). A review of teenage pregnancy in South Africa-experiences of schooling, and knowledge and access to sexual \& reproductive health services. Partners in Sexual Health, 1-63. 